\title{
Parâmetros nutricionais de novilhos sob suplementação em sistema de autocontrole de consumo no período de transição águas-seca
}

\author{
Joanis Tilemahos Zervoudakis ${ }^{1^{*}}$, Mário Fonseca Paulino ${ }^{2}$, Luciano da Silva Cabral ${ }^{3}$, Edenio \\ Detmann², Sebastião de Campos Valadares Filho², Eduardo Henrique Bevitori Kling de \\ Moraes $^{1}$
}

\footnotetext{
1 Programa de Pós-graduação em Zootecnia - UFV, Av. pH Rolfs s/n, Viçosa-MG - 36570-000.

2 DZO - Universidade Federal de Viçosa, Av. pH Rolfs s/n, Viçosa-MG - 36570-000.

${ }^{3}$ DZER - FAMEV - Universidade Federal de Mato Grosso - Av. Fernando Correa da Costa s/n. Cuiabá-MT - 78060-900.
}

RESUMO - Objetivou-se avaliar o uso de suplementos de autocontrole de consumo sobre os parâmetros nutricionais de novilhos em pastagem de Brachiaria decumbens Stapf. No período de transição águas-seca. Utilizaram-se quatro novilhos mestiços fistulados no rúmen, abomaso e esôfago. Forneceram-se sal mineral (SAL) e suplementos à base de: mistura mineral, sal comum e milho grão triturado (MGS); mistura mineral, ureia e milho grão triturado (UMG); e mistura mineral, ureia, milho grão triturado e farelo de soja (UMGFS), com diferentes teores proteicos. Os suplementos não promoveram diferenças nos consumos de nutrientes, exceto proteína bruta, cujos maiores valores foram obtidos com a utilização dos suplementos com milho grão triturado e farelo de soja. Não houve efeito dos suplementos nos parâmetros de cinética de trânsito de partículas; os valores médios encontrados para taxa de passagem ruminal e tempo médio de retenção total no trato gastrintestinal foram de $0,018 \mathrm{~h}^{-1}$ e 106,93 horas, respectivamente. A suplementação influenciou a concentração de amônia ruminal, que foi maior quando fornecidos os suplementos contendo farelo de soja (31,25 mg/dL) e milho grão triturado (24,22 mg/dL). A suplementação não influenciou as digestibilidades aparente total, ruminal e intestinal de matéria seca, matéria orgânica, carboidratos totais, fibra em detergente neutro e carboidratos não-fibrosos, mas afetou a digestibilidade aparente da proteína bruta, que foi maior no animal que recebeu o suplemento com farelo de soja. Os suplementos com mistura mineral, ureia, milho grão triturado e farelo de soja promovem maiores excreções de N-ureia e maior eficiência microbiana.

Palavras-chave: bovinos, Brachiaria decumbens, eficiência microbiana, suplementos

\section{Nutritional parameters of steers supplemented in self-control consumption system in the rainy-dry season transition period}

\begin{abstract}
The aim of this study was to evaluate the use of self-control supplements on nutritional parameters of steers grazing Brachiaria decumbens Stapf. during the rainy-dry season transitional period. Four crossbred steers fistulated in rumen, abomasum and esophagus were used. Mineral salt (SAL) and supplements based on: mineral mix, salt, and ground corn grain (GCG); mineral mix, urea and ground corn grain (UGCG); and mineral mix, urea, grounded corn grain and soybean meal (UGCSM), with different protein contents were given. The supplements did not promote significant differences for intake of nutrients except for crude protein intake whose greater values were obtained with the use of supplements of ground corn grain and soybean meal. There was no effects of the supplements on transit kinetic parameters of the particles; the mean values found for rate of passage and mean retention time in the rumen and gastrointestinal tract were $0.018 \mathrm{~h}^{-1}$ and 106.93 hours, respectively. Supplementation changed ruminal ammonia concentration whose greatest values were obtained with the supplement containing soybean meal $(31.25 \mathrm{mg} / \mathrm{dL})$ and ground corn grain $(24.22 \mathrm{mg} / \mathrm{dL})$. There was no effect of supplementation on apparent total, ruminal and intestinal digestibility of dry matter, organic matter, total carbohydrates, neutral detergent fiber and neutral detergent fiber but it affected crude protein apparent digestibility which was the highest in the animals fed supplement with soybean meal. Supplements with mineral mixture, urea, ground corn grain and soybean meal promote the highest $\mathrm{N}$-urea excretions and it shows more microbial efficiency.
\end{abstract}

Key Words: Brachiaria decumbens, cattle, microbial efficiency, supplements 


\section{Introdução}

As gramíneas forrageiras são a base da alimentação de rebanhos estabelecidos nas regiões tropicais. Contudo, nesses sistemas de produção com base em gramíneas de clima tropical, em muitas situações, a maximização da produção animal não é obtida, uma vez que ocorrem limitações relacionadas à qualidade e quantidade da forragem disponível (Reis et al., 2006).

Consequentemente, para maximização do desempenho deve-se estabelecer estratégias de fornecimento de nutrientes que viabilizem, da melhor forma possível, os padrões de crescimento estabelecidos pelo sistema de produção (Paulino, 1998).

Paulino et al. (2002) destacaram a importância de maior conhecimento do valor nutricional das gramíneas tropicais, no estabelecimento de estratégias de exploração da bovinocultura de ciclo curto em pastejo. Neste sentido, com o avançar do período seco do ano, são verificadas diferenças marcantes quanto à composição bromatológica destas gramíneas, notadamente das frações nitrogenadas.

Portanto, quando se objetiva promover, durante a fase de recria, crescimento contínuo dos animais, mantendo níveis de desempenho superiores a $700 \mathrm{~g} / \mathrm{dia}$, em sistemas de produção do "novilho superprecoce a pasto", com abate em torno de 18 a 20 meses, suplementações estratégicas durante o período de transição águas-seca podem ser utilizadas.

Vários estudos têm sido conduzidos, avaliando a utilização de misturas sal - ureia - mineral na obtenção de ganhos moderados de peso (Paulino \& Ruas, 1988; Paulino et al., 1996). Por outro lado, quando se objetiva obter maiores ganhos, a inclusão de fontes de proteína natural em misturas sal-ureia-mineral tem melhorado o desempenho dos animais (Gomes Jr. et al., 2000).
Contudo, estratégias de suplementação utilizando suplementos de auto controle de consumo têm sido predominantes durante o período seco do ano, sendo escassos os estudos avaliando o efeito destas estratégias de suplementação durante o período de transição águasseca. Objetivou-se neste estudo avaliar a influência de suplementos de autocontrole de consumo, elaborados para fornecer minerais, minerais e energia, minerais energia e compostos nitrogenados não-proteicos e minerais e, também, energia e proteína, em variáveis nutricionais com novilhos recriados a pasto durante a fase de transição entre os períodos de águas e seca.

\section{Material e Métodos}

O experimento foi conduzido nas dependências da Central de Experimentação, Pesquisa e Extensão do Triângulo - Universidade Federal de Viçosa, localizada em Capinópolis, Minas Gerais, durante o período de transição águas-seca, entre os meses de fevereiro e junho.

Foram utilizados quatro novilhos mestiços Europeu $\times$ Zebu, castrados, com peso médio inicial de $453 \mathrm{~kg}$, fistulados no esôfago, rúmen e abomaso, mantidos em quatro piquetes de 0,4 ha, cobertos uniformemente com a gramínea Brachiaria decumbens Stapf., providos de bebedouro e comedouro coberto. O experimento foi estruturado em delineamento quadrado latino, com quatro suplementos e quatro períodos experimentais com duração de 21 dias, com sete primeiros destinados à adaptação dos animais.

Os suplementos foram fornecidos à vontade, diariamente, às $10 \mathrm{~h}$, monitorando-se diariamente as quantidades fornecidas e as possíveis sobras de suplementos (Tabela 1).

Tabela 1 - Composição percentual dos suplementos, teores de nutrientes digestíveis totais e proteína bruta (\% MN)

\begin{tabular}{|c|c|c|c|c|}
\hline & \multicolumn{4}{|c|}{ Suplemento } \\
\hline & SAL & MGS & UMG & UMGFS \\
\hline & \multicolumn{4}{|c|}{ Proporção dos ingredientes (\%) } \\
\hline Ureia/sulfato de amônio (9:1) & - & - & 15 & 15 \\
\hline Sal comum & - & 15 & - & - \\
\hline Farelo de soja & - & - & - & 35 \\
\hline Nutrientes digestíveis totais $(\%)^{2}$ & - & 59,95 & 58,34 & 58,34 \\
\hline Proteína bruta (\%) & - & 6,65 & 47,69 & 61,07 \\
\hline
\end{tabular}

SAL - controle, mistura mineral; MGS - suplemento constituído de milho grão triturado, mistura mineral e sal comum; UMG - suplemento constituído de ureia/sulfato de amônio (9:1), milho grão triturado e mistura mineral; UMGFS - suplemento constituído de ureia/sulfato de amônio (9:1), milho grão triturado, farelo de soja e mistura mineral.

${ }^{1}$ Composição percentual: fosfato bicálcico, 48,61; cloreto de sódio, 48,61; sulfato de zinco, 1,46; sulfato de cobre, 0,72; sulfato de magnésio, 0,50; sulfato de cobalto, 0,05 e iodato de potássio, 0,05.

${ }^{2}$ Estimado segundo valores relatados por Valadares Filho et al. (2002). 
No primeiro dia do período experimental, foi realizada amostragem da forragem dos piquetes para avaliar a disponibilidade total de matéria seca/ha, coletando-se cinco amostras de $0,25 \mathrm{~m}^{2}$ com colheita das plantas ao nível do solo, de acordo com metodologia proposta por McMeniman (1997).

A avaliação da dieta ingerida pelos animais foi realizada utilizando-se a extrusa esofágica, que foi coletada às $7 \mathrm{~h}$, em cada período experimental, com auxílio de bolsas coletoras com fundo telado, depois que os animais foram submetidos a jejum prévio de 12 horas. As amostras foram posteriormente compostas em amostra única por animal/período.

A quantificação dos compostos degradados no rúmen e da síntese de proteína microbiana realizou-se a partir de amostras de digesta abomasal, cujas coletas seguiram a

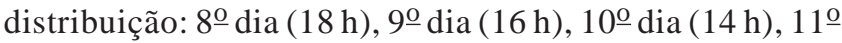
dia (12 h), 12음ia (10 h) e 13음 dia (8 h). Após secagem em estufa de ventilação forçada $\left(55^{\circ} \mathrm{C}\right)$, as amostras foram compostas, proporcionalmente, com base no peso seco ao ar, por animal/período. Para estimação do fluxo de matéria seca abomasal, foi utilizado como indicador a FDA indigestível, determinada segundo metodologia descrita por Cochran et al. (1986), estabelecendo-se a relação entre a ingestão diária do indicador e sua concentração no abomaso.

Para estimação do pH e da concentração de amônia no líquido ruminal, as amostras foram coletadas manualmente, imediatamente antes da suplementação e 6 horas após o fornecimento do suplemento, na região de interface líquido/ sólido do ambiente ruminal e filtradas por uma camada tripla de gaze. As análises de $\mathrm{pH}$ foram feitas imediatamente após a coleta por intermédio de peagâmetro digital. Para determinação de amônia, separou-se uma alíquota de $40 \mathrm{~mL}$, a qual foi adicionado $1 \mathrm{ml}$ de $\mathrm{HCl}$ 1:1, sendo acondicionada em recipiente de vidro com tampa de polietileno, identificada e congelada a $-20^{\circ} \mathrm{C}$ para posterior análise.

O isolamento de bactérias ruminais foi realizado segundo Cecava et al. (1990), imediatamente antes e 6h após o fornecimento do suplemento. Utilizou-se formaldeído P.A. como agente conservante do líquido ruminal, na proporção de $10 \mathrm{~mL} / \mathrm{L}$.

A coleta de urina, na forma de amostra spot, foi realizada quatro horas após o fornecimento do suplemento, durante micção espontânea dos animais. As amostras após diluição foram constituídas por $15 \mathrm{~mL}$ de urina e $135 \mathrm{~mL}$ de ácido sulfúrico 0,036 N, segundo Valadares et al. (1999). As amostras foram imediatamente congeladas a $-20^{\circ} \mathrm{C}$ (Valadares et al., 1999) para posterior determinação da concentração de creatinina e ureia.

O procedimento de estimação da excreção fecal e da cinética de trânsito foi baseado no fornecimento de indicador externo, em procedimento de dose única, sendo empregado como indicador o cromo mordantado à fibra, produzido conforme descrição de Udén et al. (1980). Forneceu-se fibra mordentada (100 g/animal) e coletaram-se amostras fecais nos tempos $0,6,12,18,24,30,36,42,48,60,84,108$ e 144 horas após o fornecimento do indicador, segundo recomendações de Detmann et al. (2001). A estimação da excreção fecal e da cinética de trânsito de partículas baseou-se no fornecimento, dose única, de cromo mordente à fibra, produzido conforme descrição de Udén et al. (1980). A base fibrosa para produção do indicador foi retirada de amostras de simulação manual de pastejo, obtidas entre o $5^{\circ}$ e o $10^{\circ}$ dia de cada período experimental.

Para simulação do processo inicial de mastigação, as amostras de pastejo simulado foram submetidas a um processo tríplice de moagem em moinho tipo Willey, sem a presença de peneira, visando simulação do processo de mastigação pelo animal, conforme sugerido por Detmann (2005).

A cinética de trânsito foi estimada pelo ajuste da curva de excreção fecal do indicador, do modelo unicompartimental, gama 2, tempo-dependente, descrito por France et al. (1988):

$$
C_{t}=Z(t-\tau) L^{2} \exp [-L(t-\tau)]
$$

em que: $C_{t}=$ concentração fecal do indicador no tempo $t$ (ppm); $\mathrm{t}$ = tempo após o fornecimento do indicador (horas); $\mathrm{L}$ = parâmetro taxa tempo-dependente relativo ao fluxo ruminal de partículas $\left(\mathrm{h}^{-1}\right) ; \mathrm{Z}$ = parâmetro sem interceptação biológica direta (ppm $h$ ); e $\tau=$ tempo decorrido entre a aplicação e o aparecimento do indicador nas fezes (horas).

O tempo médio de retenção total e a excreção fecal foram estimados pelas equações (France et al., 1988):

$$
\mathrm{TMRT}=\frac{2}{L}+\tau \text { e } \mathrm{EF}=\frac{D}{Z} \times 24
$$

em que: TMRT = tempo médio de retenção total (horas); $\mathrm{EF}=$ excreção fecal $(\mathrm{kg} / \mathrm{dia}) ; \mathrm{D}=$ dose de cromo $(\mathrm{mg})$; e L, Z e $\tau$ como definidos anteriormente.

A estimação do consumo voluntário foi realizada empregando-se como indicador interno a FDA indigestível. A estimação do fluxo diário de matéria seca abomasal foi feita empregando-se como indicador interno a FDA indigestível, de acordo com a equação:

$$
\mathrm{FMA}=(\mathrm{EF} \times \mathrm{CIF}) / \mathrm{CIAB}
$$

FMA = fluxo de matéria seca abomasal; CIF = concentração do indicador nas fezes $(\mathrm{kg} / \mathrm{kg})$; CIAB = concentração de indicador nas amostras de digesta abomasal $(\mathrm{kg} / \mathrm{kg})$.

Todo o material coletado foi imediatamente congelado em freezer a $-20^{\circ} \mathrm{C}$ para posteriormente ser analisado no Laboratório de Nutrição Animal do Departamento de Zootecnia da Universidade Federal de Viçosa. As análises de matéria seca (MS), matéria orgânica (MO), nitrogênio 
total (NT), extrato etéreo (EE) e lignina foram realizadas de acordo com as técnicas descritas por Silva \& Queiroz (2002). As determinações de fibra em detergente neutro (FDN) e fibra em detergente ácido (FDA) seguiram o método de extração de micro - FDN por intermédio de autoclavagem da amostra (Pell \& Shofield, 1993), com devidas correções de procedimento para a presença de amido, proteínas e cinzas (Van Soest et al., 1991). A concentração de amônia no líquido ruminal foi estimada pelo sistema micro-Kjeldahl, sem digestão ácida e utilizando-se como base para destilação o hidróxido de potássio (2N), após centrifugação prévia da amostra a $1.000 \mathrm{x}$ g, por 15 minutos. A estimação da concentração de cromo nas amostras fecais e de fibra mordantada foi realizada conforme técnica descrita por Willians et al. (1962).

A quantificação da biomassa microbiana nas amostras de rúmen e abomaso foi realizada utilizando-se bases purinas como indicadores, conforme Ushida et al. (1985). Contudo, como houve problemas encontrados durante o isolamento de bactérias ruminais, no presente estudo adotou-se a relação $\mathrm{N}$ purinas: $\mathrm{N}$ total das bactérias de 0,134 , conforme Valadares et al. (1999). Utilizaram-se como referencial para medição da eficiência de síntese de proteína microbiana as unidades: g N microbiano/kg carboidratos degradados no rúmen, g N microbiano/kg matéria orgânica aparentemente degradada no rúmen e g PB microbiana/kg de NDT consumido. Os carboidratos totais foram determinados conforme Sniffen et al. (1992).

Os carboidratos não-fibrosos (CNF) dos suplementos foram estimados de acordo com Hall (2000), utilizando desconto para porcentagem de PB oriunda de fontes de nitrogênio não protéico (NNP). O teor de nutrientes digestíveis totais (NDT observados) das dietas foi calculado pela equação proposta pelo NRC (2001). O teor de NDT estimado (NDT estimaos) foi feito de acordo com as equações citadas pelo NRC (2001).

As concentrações de creatinina, ácido úrico na urina, ureia na urina foram estimadas pelos métodos de Jaffé modificado (Bioclin K016-1), colorimétrico (UOD-PAP, Bioclin K052) e enzimático colorimétrico (Bioclin K047). O volume total urinário foi estimado empregando-se a relação entre a excreção diária de creatinina e a sua concentração nas amostras spot Chizzotti (2007).

As variáveis referentes aos parâmetros nutricionais foram analisadas em delineamento em quadrado latino, sendo as comparações entre médias de tratamentos realizadas por intermédio do teste de Newman Keulls, adotando-se o nível de significância de 5\%, conforme o modelo:

$$
\mathrm{y}_{\mathrm{ijk}}=\mu+\alpha_{\mathrm{i}}+\beta_{\mathrm{j}}+\delta_{\mathrm{k}}+\mathrm{e}_{\mathrm{ijk}},
$$
em que: $\mu$ = média constante geral; $\alpha_{i}=$ efeito do suplemento $\mathrm{i}$, considerando $\mathrm{i}=1$, 2, 3, e 4 ; $\beta_{\mathrm{j}}=$ efeito referente ao animal ou sequência de tratamentos j, em que j $=1,2,3$ e $4 ; \delta_{k}=$ efeito referente ao período experimental $\mathrm{k}$, de modo que $\mathrm{k}=1,2,3$ e 4; e $e_{\mathrm{ij}}=$ erro aleatório, associado a cada observação, pressuposto $\operatorname{NID}\left(0, \sigma^{2}\right)$.

Todas as análises foram realizadas utilizando-se o programa SAEG - UFV (1995) e, no caso do pH e das concentrações ruminais de amônia, foram realizadas subdividindo as parcelas em função dos tempos de avaliação.

\section{Resultados e Discussão}

As disponibilidades médias de matéria seca foram em torno de $9.427 \mathrm{~kg} / \mathrm{ha}$, o que corresponde à oferta média de MS de forragem de $12 \%$ do peso vivo, propiciando desta forma condições adequadas para que os animais exercessem pastejo de forma seletiva. Observaram-se valores médios quanto à composição proteica das pastagens de $8,68 \%$ PB (Tabela 2).

As associações de fontes de proteína e energia em suplementos múltiplos de autocontrole do consumo não ocasionaram diferenças nos consumos de MS, MO, MS do pasto, MO do pasto, carboidratos totais; FDN e CNF, que apresentaram valores médios de 9,01; 7,85; 8,09; 7,39; 6,86; 5,69 e 1,23 kg/dia, respectivamente (Tabela 3).

Observaram-se também efeitos significativos $(\mathrm{P}<0,05)$ dos suplementos no consumo de PB. Moore et al. (1999), em ampla revisão, avaliaram o efeito de diversos suplementos sobre a utilização de forragens, destacaram que, de forma geral, as maiores respostas à suplementação foram obtidas com a utilização de forragens de melhor qualidade e quando o consumo de PB do suplemento foi maior que $0,05 \% \mathrm{PV}$. Neste estudo, os consumos de PB do suplemento foram de 0,01; 0,09 e $0,11 \%$ do $\mathrm{PV}$, respectivamente, para os suplementos MGS, UMG e UMGFS, em decorrência de seu maior teor de PB.

Não houve efeito $(\mathrm{P}>0,05)$ dos suplementos sobre cinética de trânsito de partículas (Tabela 4), uma vez que os valores médios encontrados para a taxa de passagem ruminal e para o tempo médio de retenção total no trato gastrintestinal foram de $0,018 \mathrm{~h}^{-1} \mathrm{e} 106,93$ horas, respectivamente. Resultados semelhantes aos observados neste estudo foram encontrados por Hess et al. (1996), que não verificaram efeito da suplementação sobre a taxa de passagem de partículas, enchimento gastrintestinal e taxa de passagem de fluidos.

Adicionalmente, Brandyberry et al. (1991), utilizando 19,5\% de cloreto de sódio como agente limitante de 
Tabela 2 - Composição nutricional dos suplementos e da extrusa esofágica, com base na matéria seca

\begin{tabular}{|c|c|c|c|c|c|}
\hline & \multirow[b]{2}{*}{ Extrusa } & \multicolumn{3}{|c|}{ Suplemento } & \multirow[b]{2}{*}{ UMGFS } \\
\hline & & SAL & MGS & UMG & \\
\hline Matéria seca (\%) & 15,36 & - & 91,45 & 91,47 & 91,82 \\
\hline Matéria orgânica (\% MS) & 91,40 & - & 98,61 & 98,61 & 97,14 \\
\hline Proteína bruta (\% MS) & 8,68 & - & 6,65 & 47,69 & 61,07 \\
\hline NIDN (\% $\mathrm{N}$ total) & 6,75 & - & 5,89 & 5,89 & 4,95 \\
\hline Carboidratos totais $(\% \mathrm{MS})^{1}$ & 81,71 & - & 87,49 & 69,25 & 55,88 \\
\hline Fibra em detergente neutro (\% MS) & 69,80 & - & 10,53 & 10,53 & 9,40 \\
\hline Carboidratos não-fibrosos (\% MS) & 11,91 & - & 76,96 & 58,72 & 46,48 \\
\hline Fibra em detergente ácido (\% MS) & 31,44 & - & 2,76 & 2,76 & 4,98 \\
\hline Lignina (\% MS) & 3,80 & - & 0,15 & 0,15 & 0,41 \\
\hline Fibra em detergente ácido indigestível (\% MS) & 15,49 & - & 0,80 & 0,80 & 0,56 \\
\hline
\end{tabular}

SAL - controle, mistura mineral; MGS - suplemento constituído de milho grão triturado, mistura mineral e sal comum; UMG - suplemento constituído de ureia/sulfato de amônio (9:1), milho grão triturado e mistura mineral; UMGFS - suplemento constituído de ureia/sulfato de amônio (9:1), milho grão triturado, farelo de soja e mistura mineral.

NIDN - nitrogênio indigerível em detergente neutro; NIDA - nitrogênio indigerível em detergente ácido.

${ }^{1} \mathrm{CT}=\mathrm{FDNCP}+\mathrm{CNF}$.

Tabela 3 - Consumo médio de nutrientes, em \% PV, observados para os diferentes suplementos experimentais - animais fistulados

\begin{tabular}{|c|c|c|c|c|c|}
\hline \multirow[t]{2}{*}{ Item } & \multicolumn{4}{|c|}{ Suplemento } & \multirow[b]{2}{*}{ CV (\%) } \\
\hline & SAL & MGS & UMG & UMGFS & \\
\hline & \multicolumn{4}{|c|}{ kg.dia ${ }^{-1}$} & \\
\hline Matéria orgânica ${ }^{1}$ & 7,79 & 7,78 & 7,70 & 8,07 & 6,98 \\
\hline Matéria orgânica pasto ${ }^{1}$ & 7,79 & 7,35 & 7,23 & 7,60 & 7,30 \\
\hline Proteína bruta ${ }^{2}$ & $0,74 \mathrm{c}$ & $0,72 c$ & $0,91 b$ & $1,01 \mathrm{a}$ & 6,11 \\
\hline Carboidratos totais ${ }^{1}$ & 6,96 & 6,95 & 6,69 & 6,95 & 7,09 \\
\hline Fibra em detergente neutro ${ }^{1}$ & 5,94 & 5,66 & 5,57 & 5,85 & 7,25 \\
\hline Carboidratos não-fibrosos ${ }^{2}$ & \multicolumn{4}{|c|}{$\% \mathrm{PV}$} & \\
\hline Matéria seca ${ }^{1}$ & 1,81 & 1,93 & 1,90 & 1,97 & 5,94 \\
\hline Matéria orgânica ${ }^{1}$ & 1,65 & 1,66 & 1,65 & 1,74 & 7,58 \\
\hline Fibra em detergente neutro ${ }^{1}$ & 1,26 & 1,21 & 1,19 & 1,26 & 6,87 \\
\hline Matéria seca pasto ${ }^{1}$ & 1,81 & 1,72 & 1,69 & 1,79 & 6,54 \\
\hline Matéria orgânica pasto ${ }^{1}$ & 1,65 & 1,57 & 1,54 & 1,64 & 8,15 \\
\hline
\end{tabular}

SAL - controle, mistura mineral; MGS - suplemento constituído de milho grão triturado, mistura mineral e sal comum; UMG - suplemento constituído de ureia/sulfato de amônio (9:1), milho grão triturado e mistura mineral; UMGFS - suplemento constituído de ureia/sulfato de amônio (9:1), milho grão triturado, farelo de soja e mistura mineral.

${ }^{1}$ Efeito relativo a tratamento não-significativo pelo teste $\mathrm{F}(\mathrm{P}>0,05)$.

2 Valores seguidos com letras sobrescritas diferentes na mesma linha diferem $(\mathrm{P}<0,05)$ entre si pelo teste SNK.

consumo em suplementos múltiplos (28\% PB), não verificaram efeito da utilização de sal sobre o enchimento ruminal. Contudo, a taxa de diluição ruminal de fluídos foi maior para novilhos recebendo sal em seus suplementos, sendo as alterações no fluxo ruminal de dietas baseadas em forragem, atribuídas a elevada osmolaridade ruminal e aumento no consumo de água com o aumento dos níveis de sal.

O crescimento de bactérias celulolíticas é retardado em circunstâncias onde o pH ruminal é reduzido a níveis 
Tabela 4 - Taxa de passagem ruminal (L) e tempo médio de retenção total (TMRT) no trato gastrintestinal para os diferentes suplementos

\begin{tabular}{lccccc}
\hline Item & \multicolumn{4}{c}{ Suplementos } & \\
\cline { 2 - 5 } & SAL & MGS & UMG & UMGFS & CV(\%) \\
L $^{1}$ & 0,018 & 0,017 & 0,018 & 0,019 & 5,03 \\
TMRT $^{1}$ & 108,88 & 113,63 & 104,14 & 101,08 & 6,63 \\
\hline
\end{tabular}

SAL - controle, mistura mineral; MGS - suplemento constituído de milho grão triturado, mistura mineral e sal comum; UMG - suplemento constituído de ureia/ sulfato de amônio (9:1), milho grão triturado e mistura mineral; UMGFS suplemento constituído de ureia/sulfato de amônio (9:1), milho grão triturado, farelo de soja e mistura mineral.

${ }^{1}$ Efeito relativo a tratamento não-significativo pelo teste $\mathrm{F}(\mathrm{P}>0,05)$.

inferiores a 6,2 (Orskov, 1982). Portanto, em todos os suplementos, o pH ruminal manteve-se acima do mínimo sugerido como crítico para adequada atividade celulolítica (Tabela 5).

$\mathrm{O} \mathrm{pH}$ ruminal tem sido proposto como o principal fator para redução na digestão e consumo de forragens quando amido é fornecido na dieta de ruminantes. Contudo, as maiores proporções de milho utilizadas no suplemento MGS (70\% Milho) não prejudicaram a redução do pH ruminal dos novilhos submetidos a esta suplementação.

A suplementação influenciou a concentração de amônia ruminal $(\mathrm{P}<0,05)$ e interação suplemento $\times$ tempo $(\mathrm{P}<0,05)$, sendo observados maiores valores de $\mathrm{NH}_{3}$ para o suplemento UMGFS, seguido pelo suplemento UMG, os quais apresentaram concentrações médias ruminais de $\mathrm{NH}_{3}$ de 31,25 e 24,22 mg/dL, respectivamente, seis horas após a suplementação.

Embora os níveis ótimos de concentração de amônia ruminal ainda sejam controversos, é reconhecido que as exigências de $\mathrm{NH}_{3}$ pelos microrganismos ruminais são influenciadas pela disponibilidade e taxa de fermentação dos substratos (NRC, 1985).

Tabela 5 - pH e concentrações de amônia ruminal antes (0 hora) e 6 horas após a suplementação

\begin{tabular}{|c|c|c|c|c|}
\hline \multirow[t]{2}{*}{ Horário } & \multicolumn{4}{|c|}{ Suplemento } \\
\hline & SAL & MGS & UMG & UMGFS \\
\hline & \multicolumn{4}{|c|}{ pH ruminal ${ }^{1,2}$} \\
\hline 0 hora & $6,68 \mathrm{~B}$ & $6,68 \mathrm{~B}$ & $6,74 \mathrm{~B}$ & $6,76 \mathrm{~B}$ \\
\hline \multirow[t]{2}{*}{6 horas } & $6,92 \mathrm{~A}$ & $6,82 \mathrm{~A}$ & $6,96 \mathrm{~A}$ & $6,94 \mathrm{~A}$ \\
\hline & \multicolumn{4}{|c|}{$\mathrm{NH}_{3}$ ruminal ${ }^{1,2}$} \\
\hline 0 hora & $4,90 \mathrm{Ab}$ & $4,38 \mathrm{Ab}$ & $7,26 \mathrm{Bb}$ & $17,61 \mathrm{Ba}$ \\
\hline 6 horas & 6,49Ac & $4,81 \mathrm{Ac}$ & $24,22 \mathrm{Ab}$ & $31,35 \mathrm{Aa}$ \\
\hline
\end{tabular}

SAL - controle, mistura mineral; MGS - suplemento constituído de milho grão triturado, mistura mineral e sal comum; UMG - suplemento constituído de ureia/ sulfato de amônio (9:1), milho grão triturado e mistura mineral; UMGFS suplemento constituído de ureia/sulfato de amônio (9:1), milho grão triturado, farelo de soja e mistura mineral.

${ }^{1}$ Valores seguidos com letras minúsculas diferentes na mesma linha diferem entre si pelo teste SNK $(\mathrm{P}<0,05)$.

2 Valores seguidos com letras maiúsculas diferentes na mesma coluna diferem $(\mathrm{P}<0,05)$ entre si pelo teste SNK.
Apenas nos suplementos SAL, UMG e UMGFS, as concentrações de amônia ruminal após seis horas mantiveram-se em níveis acima de $5 \mathrm{mg} / \mathrm{dL}$ de líquido ruminal (Satter \& Slyter, 1974), considerados como mínimos para adequada fermentação ruminal da fibra. Entretanto, quando considerados os valores de concentração de amônia ruminal preconizados por Leng (1990), 10 mg/dL de líquido ruminal, como ideais para maximização do consumo voluntário em condições tropicais, somente os suplementos UMG e UMGFS apresentaram concentrações superiores aos valores sugeridos.

Destacaram-se as baixas concentrações de $\mathrm{NH}_{3}$ ruminal verificadas pelo fornecimento do suplemento MGS, o qual possuía grande proporção de milho em sua composição (70\%). Zinn \& Owens (1983) ressaltaram que baixas concentrações de amônia ruminal observadas pelo fornecimento de suplementos com grandes quantidades de milho pode estar relacionadas à menor degradabilidade ruminal da proteína do milho. Além disso, competição direta por nitrogênio entre bactérias amilolíticas e celulolíticas pode posteriormente limitar a celulólise ruminal.

Nesse enfoque, suplementos contendo milho e com inadequada proteína degradada no rúmen induziriam baixas concentrações de amônia ruminal que poderiam reduzir o crescimento microbiano, prejudicando com isso a digestão da fibra. Posteriormente, os microrganismos fermentariam a forragem mais lentamente, retardando com isso a taxa de passagem e reduzindo tanto o consumo como o desempenho dos animais.

Resultados semelhantes aos encontrados no presente estudo foram observados por Bodine \& Purves (2003), que em amplo estudo avaliando diferentes associações de proteína e energia em suplementos múltiplos, ressaltaram ausência de resultados positivos pela adição de farelo de soja (PDR) sobre o consumo e taxa de passagem, quando comparados ao suplemento contendo milho como ingrediente basal e com inadequada concentração de proteína degradável no rúmen.

De acordo com Bodine \& Purves (2003), os resultados obtidos podem ser atribuídos a alterações no comportamento de pastejo dos animais, a ampla oportunidade de seleção da dieta pelos animais em pastejo e às altas variações associadas com a utilização de dados provenientes de indicadores, ou alguma combinação desss fatores. Por outro lado, Elizalde et al. (1999) ressaltaram que a redução na digestão de forragens com a adição de grãos aumenta de acordo com o teor de fibra da forragem basal ou quando a qualidade desta forragem diminui, possivelmente devido aos microrganismos digestores de fibra contribuírem mais 
para a digestão de forragens de baixa qualidade que para forragens de qualidade superior.

Neste contexto, Griswold et al. (2003) não verificaram efeito dos níveis de ureia e proteína degradável no rúmen sobre a digestibilidade de FDN ou de carboidratos nãofibrosos. Adicionalmente, os referidos autores sugeriram que nas circunstâncias em que foram conduzidos seus estudos, as bactérias que degradam hemicelulose teriam sido capazes de competir de forma efetiva com as bactérias que degradam carboidratos não-estruturais pelo nitrogênio proveniente de peptídeos e aminoácidos, quando o nitrogênio foi limitante, suportando desta forma, um tamanho populacional suficiente para degradar efetivamente a hemicelulose da dieta. Nestas circunstâncias o nitrogênio amoniacal poderia ser necessário apenas para suportar crescimento e atividade de bactérias celulolíticas.

Não se observou efeito dos suplementos $(\mathrm{P}>0,05)$ sobre as digestibilidades aparente total, ruminal e intestinal da MS, MO, PB, CT, FDN e CNF (Tabela 6). Resultados próximos aos obtidos neste estudo foram observados por Chico et al. (1971), que, utilizando suplemento basal e suplemento contendo $30 \%$ de sal branco em substituição aos ingredientes do suplemento basal, não encontraram diferenças entre os suplementos quanto a digestibilidade aparente da MS, celulose e proteína.

Os valores de NDT observados foram superiores aos de NDT estimados, em decorrência do efeito associativo entre alimentos, que pode ter contribuído para uma melhor dinâmica na degradabilidade ruminal dos nutrientes, quando foram utilizados mistura de ingredientes e/ou alimentos (Tabela 6).

Neste estudo verificaram-se diferenças significativas entre os suplementos quanto à digestibilidade ruminal da $\mathrm{PB}$, que foi maior para o suplemento UMGFS e que pode ser explicada pelo efeito direto do maior consumo de $\mathrm{PB}$ neste tratamento, evidenciado pelas maiores concentrações de nitrogênio amoniacal ruminal - $\mathrm{NH}_{3}$ (Tabela 5) e pela excreção de ureia e $\mathrm{N}$-ureia (Tabela 7).

Houve efeito dos suplementos $(\mathrm{P}<0,05)$ sobre a excreção urinária de ureia e de $\mathrm{N}$-ureia (Tabela 7). Neste sentido, a excreção de N-ureia aumentou de acordo com o nível proteico dos suplementos e foi maior para o suplemento UMGFS (90,03 g/dia), indicando que possivelmente não houve sincronização adequada entre a

Tabela 6 - Digestibilidade dos nutrientes e NDT observado e estimado das dietas experimentais

\begin{tabular}{|c|c|c|c|c|c|}
\hline & \multicolumn{4}{|c|}{ Suplemento } & \multirow[b]{2}{*}{$\mathrm{CV}(\%)$} \\
\hline & SAL & MGS & UMG & UMGFS & \\
\hline & \multicolumn{3}{|c|}{ Digestibilidade total (\%) } & & \\
\hline Matéria seca (\% do total ingerido) & 56,24 & 59,09 & 57,79 & 59,63 & 5,11 \\
\hline Matéria orgânica (\% do total ingerido) & 54,80 & 55,25 & 53,48 & 56,29 & 5,77 \\
\hline Proteína bruta (\% do total ingerido) & 46,60 & 46,41 & 54,55 & 56,11 & 13,66 \\
\hline Carboidratos totais (\% do total ingerido) & 57,62 & 59,20 & 56,64 & 58,54 & 6,45 \\
\hline Fibra em detergente neutro (\% do total ingerido) & 61,89 & 56,70 & 56,91 & 58,70 & 5,88 \\
\hline \multirow[t]{2}{*}{ Carboidratos não-fibrosos (\% do total ingerido) } & 56,14 & 78,47 & 73,01 & 69,30 & 14,47 \\
\hline & \multicolumn{3}{|c|}{ Digestibilidade ruminal } & & \\
\hline Matéria seca (\% do total ingerido) $)^{2}$ & 46,48 & 49,41 & 44,39 & 47,12 & 6,50 \\
\hline Matéria orgânica (\% do total ingerido) ${ }^{2}$ & 42,92 & 41,03 & 39,30 & 42,09 & 10,59 \\
\hline Proteína bruta ${ }^{1,3}$ & $7,50^{\mathrm{b}}$ & $8,63^{b}$ & $15,05^{b}$ & $27,42^{\mathrm{a}}$ & 42,94 \\
\hline Carboidratos totais (\% do total ingerido) ${ }^{2}$ & 54,22 & 51,73 & 48,23 & 49,78 & 5,73 \\
\hline Fibra em detergente neutro ( $\%$ do total ingerido $)^{2}$ & 57,22 & 54,31 & 51,66 & 54,10 & 6,14 \\
\hline \multirow[t]{2}{*}{ Carboidratos não-fibrosos (\% do total ingerido) ${ }^{2}$} & 29,25 & 29,45 & 38,29 & 32,73 & 31,35 \\
\hline & \multicolumn{3}{|c|}{ Digestibilidade intestinal } & & \\
\hline Matéria seca (\% do total ingerido) ${ }^{2}$ & 9,76 & 9,68 & 13,40 & 12,51 & 27,58 \\
\hline Matéria orgânica (\% do total ingerido) ${ }^{2}$ & 11,88 & 14,22 & 14,18 & 14,20 & 24,01 \\
\hline Proteína bruta ${ }^{1,2}$ & 49,45 & 50,72 & 50,65 & 56,29 & 20,46 \\
\hline Carboidratos totais (\% do total ingerido) ${ }^{2}$ & 3,40 & 7,47 & 8,41 & 8,76 & 58,56 \\
\hline Fibra em detergente neutro (\% do total ingerido $)^{2}$ & 4,67 & 2,39 & 5,25 & 4,60 & 61,96 \\
\hline \multirow[t]{2}{*}{ Carboidratos não-fibrosos (\% do total ingerido) ${ }^{2}$} & 26,89 & 49,02 & 34,72 & 36,57 & 36,92 \\
\hline & Extrusa & & Dietas & & \\
\hline NDT observados & 55,18 & 57,89 & 58,80 & 58,88 & - \\
\hline NDT estimados ${ }^{4}$ & 51,40 & 52,21 & 52,21 & 52,00 & - \\
\hline
\end{tabular}

SAL - controle, mistura mineral; MGS - suplemento constituído de milho grão triturado, mistura mineral e sal comum; UMG - suplemento constituído de ureia/sulfato de amônio (9:1), milho grão triturado e mistura mineral; UMGFS - suplemento constituído de ureia/sulfato de amônio (9:1), milho grão triturado, farelo de soja e mistura mineral.

${ }^{1} \mathrm{Em} \%$ da quantidade que chegou no local.

2 Efeito não-significativo $(\mathrm{P}>0,05)$ de tratamento pelo teste $\mathrm{F}$.

3 Valores seguidos com letras sobrescritas diferentes na mesma linha diferem $(\mathrm{P}<0,05)$ entre si pelo teste SNK.

${ }^{4}$ NDT EST - NDT estimado segundo NRC (2001). 
Tabela 7 - Excreção urinária de ureia e N-ureia e eficiência microbiana

\begin{tabular}{|c|c|c|c|c|c|}
\hline \multirow[t]{2}{*}{ Item } & \multicolumn{4}{|c|}{ Suplemento } & \multirow[b]{2}{*}{ CV (\%) } \\
\hline & SAL & MGS & UMG & UMGFS & \\
\hline Ureia (g/dia) & $51,83 b$ & $65,03 \mathrm{~b}$ & $103,55 \mathrm{ab}$ & $193,20 a$ & 55,06 \\
\hline N - Ureia (g/dia) & $24,15 b$ & $30,30 b$ & $48,25 \mathrm{ab}$ & $90,03 a$ & 55,06 \\
\hline \multicolumn{6}{|c|}{ Eficiência microbiana } \\
\hline g $\mathrm{N}$ microbiano/kg de carboidratos totais digeríveis no rúmen & $22,93 \mathrm{c}$ & $24,94 b c$ & $26,89 b$ & $30,14 a$ & 5,62 \\
\hline Nitrogênio total (g/dia) & $159,62 b$ & $168,80 \mathrm{ab}$ & $169,67 b$ & $216,49 a$ & 5,82 \\
\hline Nitrogênio microbiano (g/dia) & $88,27 b$ & 88,03b & $91,69 b$ & $107,31 \mathrm{a}$ & 12,55 \\
\hline
\end{tabular}

Valores seguidos com letras sobrescritas diferentes na mesma linha diferem $(\mathrm{P}<0,05)$ entre si pelo teste SNK.

energia gerada para o crescimento microbiano com a degradação mais rápida da proteína.

Um dos elementos-chave na eficiência de conversão de forragens a produto animal é a sincronização entre o suprimento de amônia e o suprimento de substratos energéticos provenientes da digestão da forragem (Dove, 1996). Em baixa disponibilidade de energia e alta de proteína, elevadas quantidades de aminoácidos provenientes da proteólise são deaminadas e utilizadas como fonte de energia (Russell et al., 1992). Consequentemente, em decorrência da maior produção de amônia, seu excesso é excretado na forma de ureia na urina.

Verificou-se efeito significativo da suplementação sobre a eficiência microbiana expressa nas diferentes formas $(\mathrm{P}<0,05)$, sendo que o suplemento UMGFS apresentou valores superiores aos demais tratamentos, para a eficiência microbiana expressa em g N microbiano/kg CTDR e em g PB microbiana/100g NDT, que foram de 30,14 g e 13,10, respectivamente (Tabela 7).

Os valores médios obtidos para produção de PB microbiana pelo fornecimento do suplemento UMGFS (13,10 g PB microbiana/100g NDT) foram próximos aos valores de eficiência microbiana de 13,0 g PB microbiana/ $100 \mathrm{~g}$ NDT, preconizados pelo NRC (2001). Adicionalmente, as maiores eficiências microbianas obtidas com o fornecimento de farelo de soja no suplemento UMGFS em comparação com o suplemento UMG, possivelmente foram observadas em função do fornecimento de aminoácidos e peptídeos pela suplementação com UMGFS em relação ao fornecimento somente de $\mathrm{N}$ amoniacal (UMG).

Dentro deste enfoque, Hoover \& Stockes (1991) ressaltaram que o fornecimento de aminoácidos, peptídeos e misturas de aminoácidos e peptídeos, melhoram o crescimento microbiano em relação ao meio contendo somente $\mathrm{N}$ - amoniacal, destacando que o ótimo crescimento microbiano é dependente da disponibilidade de formas orgânicas de N.

Neste sentido, os menores valores encontrados para eficiência microbiana expresso em função do CTDR para o suplemento MGS em relação ao suplemento UMGFS (Tabela 7), são condizentes com as afirmações de Hespell (1983), citados por Hoover \& Stockes (1991), de que extensivas fermentações de carboidratos podem ocorrer em culturas com inadequadas concentrações de $\mathrm{N}$, mas o crescimento microbiano será limitado devido a um desacoplamento entre energia e proteína, resultando em baixa produção de proteína microbiana por unidade de carboidrato digerido.

Adicionalmente, Griswold et al. (2003), conduzindo estudos em fermentadores, verificaram que aumentos na digestão de nitrogênio pela infusão de ureia causaram elevações nas concentrações de nitrogênio amoniacal e reduções nas concentrações de $\mathrm{N}$ - peptídeos, sugerindo que $\mathrm{N}$ - peptídeos teriam sido a principal forma nitrogenada limitando o crescimento microbiano (Griswold et al., 2003).

A suplementação teve efeito significativo $(\mathrm{P}<0,05)$ sobre os fluxos de nitrogênio total e nitrogênio microbiano, uma vez que os maiores valores foram obtidos com o suplemento contendo farelo de soja, 216,49 e 107,31 g/dia, respectivamente, para nitrogênio total enitrogênio microbiano.

\section{Conclusões}

Suplementos de autocontrole de consumo com maiores níveis proteicos, contendo fontes naturais de proteína (farelo de soja) e com consumo médio de $1 \mathrm{~kg} /$ dia propiciam maiores valores de eficiência de síntese de proteína microbiana e fluxos de nitrogênio total e microbiano. Suplementos de autocontrole de consumo e contendo altas proporções de milho (mineral - energético) devem ser exaustivamente avaliados. 


\section{Referências}

BODINE, T.N.; PURVIS II, H.T. Effects of supplemental energy and/or degradable intake protein on performance, grazing behavior, intake, digestibility, and fecal and blood indices by beef steers grazed on dormant native tallgrass prairie. Journal of Animal Science, v.81, p.304-317, 2003.

BRANDBYBERRY, S.D.; COCHRAN, R.C.; VANZANT, E.S. et al. Influence of supplementation method on forage use and grazing behavior by beef cattle grazing bluestem range. Journal of Animal Science, v.69, p.4128-4136, 1991.

CECAVA, J.M.; MERCHEN, N.R., GAY, L.C. et al. Composition of ruminal bacteria harvested from steers as influenced by dietary energy level, feeding frequency, and isolation techniques. Journal of Dairy Science, v.73, n.9, p.2480-2488, 1990.

CHICO, C.F.; SHULTZ, T.A.; RIOS, J. Self-feeding salt supplement to grazing steers under tropical conditions. Journal of Animal Science, v.33, p.142-146, 1971.

CHIZZOTTI, M.L.; VALADARES FILHO, S.C.; VALADARES, R.F.D. et al. Consumo, digestibilidade e excreção de ureia e derivados de purina em vacas de diferentes produções de leite. Revista Brasileira de Zootecnia, v.36, n.4, p.138-146, 2007.

COCHRAN, R.C.; ADAMS, D.C.; WALLACE, J.D. et al. Predicting digestibility of different diets with internal markers: Evaluation of four potential markers. Journal of Animal Science, v.63, n.5, p.1476-1483, 1986.

DETMANN, E.; PAULinO, M.F.; CECON, P.R. et al. Níveis de Proteína em suplementos para terminação de bovinos em pastejo durante o período de transição seca/águas: Consumo voluntário e trânsito de partículas. Revista Brasileira de Zootecnia, v.34. n.4, p.1371-1379, 2005.

DETMANN, E.; CECON, P.R.; PAULINO, M.F. et al. Estimação de parâmetros da cinética de trânsito de partículas em bovinos sob pastejo por diferentes seqüências amostrais. Revista Brasileira de Zootecnia, v.30, n.1, p.222-230, 2001.

DOVE, H. The ruminant, the rumen and the pasture resource: nutrient interactions in the grazing animal. In: HODGSON, J.; ILLUS, A.W. (Eds.) The ecology and management of grazing systems. Wallingford: CAB Internacional, 1996. p.219-246.

ELIZALDE, J.C.; MERCHEN, N.R.; FAULKNER, D.B. Supplemental cracked corn for steers fed fresh alfafa: I. Effects on digestion of organic matter, fiber, and starch. Journal of Animal Science, v.77, p.457-466, 1999.

FRANCE, J.; DHANOA, M.S.; SIDDONS, R.C. et al. Estimating the fecal producing by ruminants from faecal marker concentration curves. Journal of Theoretical Biology, v.135, n.2, p.383-391, 1988.

GOMES JR., P.; PAULINO, M.F.; DETMANN, E. et al. Fontes de proteínas em suplementos múltiplos para recria de novilhos durante a época seca. In: REUNIÃO ANUAL DA SOCIEDADE BRASILEIRA DE ZOOTECNIA, 38., 2001, Piracicaba. Anais... Piracicaba: Sociedade Brasileira de Zootecnia, 2001. (CD-ROM).

GRISWOLD, K.E.; APGAR, G.A.; BOUTON, J. et al. Effects of urea infusion and ruminal degradable protein concentration on microbial growth, digestibility, and fermentation in continuous culture. Journal of Animal Science, v.81, p.329-336, 2003.

HALL, M.B. Calculation of non-structural carbohydrate content of feeds that contain no-protein nitrogen. Gainesville: University of Florida, 2000. p.A-25 (Bulletin, 339).

HESS, B.W.; KRYSL, L.J.; JUDKINS, M.B. et al. Supplemental corn or wheat bran for steers grazing endophyte-free fescue pasture: effects on live weight gain, nutrient quality, forage intake, particulate and fluid kinetics, ruminal fermentation, and digestion. Journal of Animal Science, v.74, p.1116-1125, 1996.

HOOVER, W.H.; STOKES, S.R. Balancing carbohydrates and proteins for optimum rumen microbial yield. Journal of Dairy Science, v.74, p.3630-3644, 1991.
KRYSL, L.J.; HESS, B.W. Influence of supplementation on behavior of grazing cattle. Journal of Animal Science, v.71, p.2546-2555, 1993.

LENG, R.A. Factors affecting the utilization of "poor-quality" forages by ruminants particularly under tropical conditions. Nutrition Research Review, v.3, p.277-303, 1990.

McMENIMAN, N.P. Methods of estimating intake of grazing animals. In: REUNIÃO ANUAL DA SOCIEDADE RASILEIRA DE ZOOTECNIA, 34., 1997, Juiz de Fora. Anais... Juiz de Fora: SBZ, 1997. p.131-168.

MOORE, J.E.; BRANT, M.H.; KUNKLE, W.E.; et al. Effects of supplementation on voluntary forage intake, diet digestibility, and animal performance. Journal of Animal Science, v.77, p.122-135, 1999 (supl. 2.).

NATIONAL RESEARCH COUNCIL - NRC. Nutrients requirements of dairy cattle. 7.ed. Washington, D.C.: National Academy Press, 2001. 381p.

NATIONAL RESEARCH COUNCIL - NRC. Ruminant nitrogen usage. Washington, D.C.: National Academy Pres, 1985. 138p.

ORSKOV, E.R. Protein nutrition in ruminants. New York: Academic Press, 1982. 178p.

PAULINO, M.F.; ZERVOUDAKIS, J.T.; MORAES, E.H.K.B. et al. Bovinocultura de ciclo curto em pastagens. In: SIMPÓSIO DE PRODUÇÃO DE GADO DE CORTE, 3., 2002, Viçosa, MG. Anais... Viçosa, MG, 2002. p.153-196.

PAULINO, M.F. Suplementos múltiplos para recria e engorda de bovinos em pastagens. In: CONGRESSO NACIONAL DOS ESTUDANTES DE ZOOTECNIA, 1998, Viçosa, MG. Anais.. Viçosa, MG: Associação Mineira dos Estudantes de Zootecnia, 1998. p.173-188.

PAULINO, M.F.; BORGES, L.E.; CARVALHO, P.P. et al. Cloreto de sódio em suplementos múltiplos sobre o desenvolvimento de novilhos mestiços em pastejo, durante a época seca. In: REUNIÃO ANUAL DA SOCIEDADE BRASILEIRA DE ZOOTECNIA, 33., 1996, Fortaleza. Anais... Fortaleza: Sociedade Brasileira de Zootecnia, 1996. p.19-20.

PAULINO, M.F.; RUAS, J.R.M. Considerações sobre a recria de bovinos de corte. Informe Agropecuário, v.13, n.153/154, p.68-80, 1988.

PELL, A.N.; SCHOFIELD, P. Computerized monitoring of gas production to measure forage digestion in vitro. Journal of Dairy Science, v.76, n.4, p.1063-1073, 1993.

REIS, R.A.; TEIXEIRA, I.A.M.A.; SIQUEIRA, G.R. Impacto da Qualidade da Forragem na Produção Animal. In: REUNIÃO ANUAL DA SOCIEDADE BRASILEIRA DE ZOOTECNIA, 43. 2006, João Pessoa. Anais... João Pessoa: SBZ, 2006. (CD-ROM)

RUSSELL, J.B.; O’CONNOR, J.D.; FOX, D.G. et al. A net carbohydrate and protein system for evaluating cattle diets: I. Ruminal fermentation. Journal of Animal Science, v.70 n.12, p.3551-3561, 1992.

SATTER, L.D.; SLYTER, L.L. Effect of ammonia concentration on rumen microbial protein production in vitro. British Journal Nutritional, v.32, p.199, 1974

SILVA, D.J.; QUEIROZ, A.C. Análise de alimentos: métodos químicos e biológicos. 3.ed. Viçosa, MG: UFV, Imprensa Universitária, 2002. 165p.

SNIFFEN, C.J.; O’CONNOR, J.D.; VAN SOEST, P.J. et al. A net carbohydrate and protein system for evaluating cattle diets: II. Carbohydrate and protein availability. Journal of Animal Science, v.70, p.3562-3577, 1992.

UDÉN, P.; COLUCCI, P.E.; VAN SOEST, P.J. Investigation of chromium, cerium and cobalt as markers in digesta. Rate of passage studies. Journal of the Science and Food Agriculture, v.31, n.7, p.625-632, 1980.

UNIVERSIDADE FEDERAL DE VIÇOSA - UFV. SAEG - Sistema de análises estatísticas e genética. Viçosa, MG, 1995. (Apostila). 59p.

USHIDA, K.; LASSALAS, B.; JOUANY, J.P. Determination of assay parameters for RNA analysis in bacterial and duodenal samples by 
spectrophotometry. Influence of treatment and preservation. Reproduction Nutrition Development, v.25, p.1037-1046, 1985. VALADARES, R.F.D.; BRODERICK, G.A.; VALADARES FILHO, S.C. et al. Effect of replacing alfalfa silage with high moisture corn on ruminal protein synthesis estimated from excretion of total purine derivatives. Journal of Dairy Science, v.82, n.11, p.2686-2696, 1999.

VALADARES FILHO, S.C.; ROCHA JR., V.R.; CAPELLE, E.R. CQBAL 2.0. Tabelas brasileiras de composição de alimentos para bovinos. Viçosa, MG: Gráfica Suprema, 2002. 279p.
VAN SOEST, P.J.; ROBERTSON, J.B.; LEWIS, B.A. Methods for dietary fiber, and nonstarch polysaccharides in relation to animal nutrition. Journal of Dairy Science, v.74, n.10, p.3583-3597, 1991.

WILLIANS, C.H.; DAVID, D.J.; IISMA, O. The determination of chromic oxide in faeces samples by atomic absorption spectrophotometry. Journal of Agricultural Science, v.59, n.3, p.381-385, 1962.

ZINN, R.A.; OWENS, F.N. Site de protein digestion in steers: Predictability. Journal of Animal Science, v.56, p.707, 1983. 